\title{
The Welfare Cost of Bank Capital Requirements
}

\author{
Skander Van Den Heuvel ${ }^{1}$ \\ The Wharton School, University of Pennsylvania
}

January, 2005

\begin{abstract}
This paper estimates the welfare cost of bank capital requirements and finds that the macroeconomic stakes involved with the design of capital adequacy regulation are potentially large. A general equilibrium model with capital accumulation and a preference for liquidity is developed. Banks provide liquidity services by accepting deposits. A capital requirement plays a role, as it limits the moral hazard on the part of banks that is induced by the presence of a deposit insurance scheme. However, ceteris paribus, a higher capital requirement implies that banks can accept fewer deposits and thus provide fewer liquidity services to households. It is shown that equilibrium asset returns reveal the strength of households' preferences for liquidity and this allows the derivation of a formula for the welfare cost of capital requirements that is a function only of observable variables. Using U.S. banking data, the cost of increasing the capital requirement by 10 percentage points is equivalent to a permanent loss in consumption of at least 0.1 to 0.2 percent.
\end{abstract}

${ }^{1}$ Finance Department, Wharton School, 3620 Locust Walk, Philadelphia, PA 19104, USA. Email: vdheuvel@wharton.upenn.edu. The author has benefited from helpful comments from Andy Abel, Joao Gomes, Gary Gorton and seminar participants at Wharton and the Federal Reserve Board. All mistakes are mine. 
This paper asks, and provides an answer to, the following question: How large are the welfare costs of bank capital requirements? While there are a number of papers on the theoretical benefits of capital adequacy regulation, based on limiting the moral hazard involved with deposit insurance ${ }^{2}$ or externalities associated with bank failures, much less is known about whether there are also costs involved with imposing restrictions on the capital structure of banks. Recent work by Diamond and Rajan (2000) and Gorton and Winton (2000), among others, suggests that capital requirements may have an important cost in that they reduce the ability of banks to create liquidity by accepting deposits. After all, a capital requirement limits the fraction of bank assets that can be financed by issuing deposit-type liabilities. Unfortunately, the models in these papers do not easily lend themselves to a quantification of this cost.

This paper's contribution is to model the benefit of liquidity creation in a flexible way, embed the role of liquidity creating banks in an otherwise standard general equilibrium growth model, and use that framework to quantify the welfare cost of increasing the capital requirement. This cost depends crucially on households' preferences for liquidity. A key insight from the model is that equilibrium asset returns reveal the strength of these preferences for liquidity and this allows us to quantify the welfare cost. The model also incorporates a rationale for the existence of capital adequacy regulation, based on a moral hazard problem associated with deposit insurance. The resulting benefits are characterized, but are harder to quantify.

In many countries capital adequacy regulation is currently based on the Basel Accords. In response to perceived shortcomings in the original Accord, practitioners have added more and more detailed refinements, culminating in the soon-to-be implemented Basel 2, while attempting to keep the required ratio of capital to risk weighted assets for a typical bank approximately the same. But is the $8 \%$ of the original Basle Accord a good number for the total risk-based capital ratio? This fundamental question remains unaddressed in the literature. At the same time the changes involved in Basel 2 seem likely to greatly increase the cost of compliance and supervision of banks.

If we find that the welfare cost of capital requirements are trivial, this could be an argument for creating a simple, robust system of capital adequacy

\footnotetext{
${ }^{2}$ See, for example, Giammarino, Lewis, and Sappington (1993) and Dewatripont and Tirole (1994). See Allen and Gale (2003) for a more skeptical view. Diamond and Dybvig (1983) is often viewed as a theoretical justification for deposit insurance.
} 
regulation, with low compliance and supervision costs, but with relatively high capital ratios so as to make bank failure a sufficiently infrequent event. On the other hand, if we find a high welfare cost of capital requirements, this could be an argument for lowering them, by either accepting a higher chance of bank failure, or by designing a more risk-sensitive system with the associated increased supervision and compliance costs, which seems to be the trend in practice.

\section{The model}

The most important respect in which the model deviates from the standard growth model is that households have a need for liquidity, and that certain agents, called banks, are able to create financial assets, called deposits, which provide liquidity services. Since a central goal of the model is to provide a framework not just for illustrating, but for actually measuring the welfare cost of capital requirements, it is important to model the preferences for liquidity in a way that is not too restrictive. In as much as possible, we would like the data to provide the answer, not the specific modeling choices. To that end, I follow Sidrauski (1967) in adopting the modeling device of putting liquidity services in the utility function. This has two disadvantages and one advantage.

One disadvantage is that it does not further our understanding of why households like liquid assets, but this is not the topic of this paper, so this concern can be dismissed. ${ }^{3}$ A second disadvantage is that if one needs to specify a particular functional form for the utility function, one is on loose grounds. For example, is the marginal utility of consumption increasing or decreasing in deposits?

Fortunately - and this is the advantage of this approach - there is no need to make unpalatable assumptions of this kind. I will show that it is possible to derive a first-order approximation the welfare cost of raising the capital requirement without making any assumptions on the functional form of the utility function, beyond the standard assumptions that it is increasing and concave. A trade-off involved with modeling liquidity in this flexible way, and embedding it in a general equilibrium analysis, is that the modeling of the banks' assets is not rich enough to incorporate the details of risk-based capital requirements.

\footnotetext{
${ }^{3}$ Nonetheless, see Feenstra (1986) for how optimizing models of money demand based on a Baumol Tobin transaction technology can be approximately rewritten as maximization problems with money in the utility function.
} 


\section{The environment and the agents' decision problems}

Time is discrete and there are infinitely many periods. The economy consists of households, banks, (nonfinancial) firms, and a government or regulatory agent. Households own both the banks and the nonfinancial firms. These firms combine capital and labor to produce the single good which households consume. I now discuss the assumptions for each of these agents, and analyze their decision problems in turn.

Households: There is a continuum of households with mass one. Households are infinitely lived dynasties and have identical preferences. They value consumption and liquidity services. Households can obtain these liquidity services by allocating some of their wealth to bank deposits, an asset created by banks for this purpose. As mentioned, the liquidity services of bank deposits are modeled by assuming that the household's utility function is increasing in the amount of deposits.

Besides holding bank deposits, denoted $d_{t}$, households can store their wealth by buying and selling shares, or equity, $e_{t}$. They supply a fixed quantity of labor, normalized to one, for a wage, $w_{t}$. Taxes are lump-sum and equal to $T_{t}$. There is no aggregate uncertainty, so the representative household's problem is one of perfect foresight:

$$
\begin{array}{ll}
\max _{\left\{c_{t}, d_{t}\right\}_{t=0}^{\infty}} & \sum_{t=0}^{\infty} \beta^{t} u\left(c_{t}, d_{t}\right) \\
\text { s.t. } & d_{t+1}+e_{t+1}+c_{t}=w_{t} 1+R_{t}^{D} d_{t}+R_{t}^{E} e_{t}-T_{t} \\
& \lim _{T \rightarrow \infty}\left(\prod_{s=0}^{T} R_{s}^{E}\right)^{-1}\left(d_{T}+e_{T}\right) \geq 0 \\
& d_{0}+e_{0} \equiv a_{0} \text { given }
\end{array}
$$

where $c_{t}$ is consumption in period $t, R_{t}^{D}$ is the return on bank deposits, $R_{t}^{E}$ is the return on (bank or firm) equity, and $\beta$ is the subjective discount factor. The returns $R_{t}^{D}$ and $R_{t}^{E}$, and the wage are determined competitively, so the household takes these as given. The same applies for the taxes. There is no distinction between bank and nonbank equity, since, in the absence of risk, they are perfect 
substitutes for the household and will thus also command the same return. The second constraint is a no-Ponzi game condition, the third an initial condition.

The utility function is assumed to be concave, at least once continuously differentiable on $\mathbb{R}_{++}^{2}$ and increasing on its domain in both arguments, and strictly increasing in consumption:

$$
u_{c}(c, d) \equiv \partial u(c, d) / \partial c>0 \quad \text { and } \quad u_{d}(c, d) \equiv \partial u(c, d) / \partial d \geq 0
$$

The first-order conditions to the household's problem are:

$$
\begin{aligned}
& u_{c}\left(c_{t}, d_{t}\right)=\lambda_{t} \\
& u_{d}\left(c_{t}, d_{t}\right)+\lambda_{t} R_{t}^{D}-\beta^{-1} \lambda_{t-1}=0 \\
& \lambda_{t} R_{t}^{E}-\beta^{-1} \lambda_{t-1}=0
\end{aligned}
$$

where $\lambda_{t}$ is the Lagrange multiplier associated with the intertemporal budget constraint (1). Rewriting this,

$$
\begin{aligned}
& R_{t}^{E}=\beta^{-1}\left(u_{c}\left(c_{t-1}, d_{t-1}\right) / u_{c}\left(c_{t}, d_{t}\right)\right) \\
& u_{d}\left(c_{t}, d_{t}\right)=u_{c}\left(c_{t}, d_{t}\right)\left(R_{t}^{E}-R_{t}^{D}\right)
\end{aligned}
$$

Equation (2), which determines the return on equity, is the standard Euler equation for the intertemporal consumption-saving choice in a deterministic setting, with one difference: the marginal utility of consumption may depend on the level of deposits. Equation (3) relates the spread between the return on equity and the return on bank deposits to the marginal value of the liquidity services provided by deposits, expressed in units of the consumption good. If $u_{d}(c, d)>0$, then the return on equity will be higher than the return on deposits to compensate for the fact that equity does not provide any liquidity services.

Banks: There is a continuum of banks with mass one, which make loans to nonfinancial firms and finance these loans by accepting deposits from households and issuing equity. The ability of banks to create liquidity through deposit contracts is their defining feature. All contracts are resolved in one period. Every period new banks are setup with free entry into banking. The balance sheet, and the notation, for the representative bank during period $t$ is: 


\begin{tabular}{ll|ll}
\multicolumn{2}{l}{ Assets } & \multicolumn{2}{l}{ Liabilities } \\
\hline$L_{t} \quad$ Loans & $D_{t}$ & Deposits \\
& $E_{t}$ & Equity
\end{tabular}

Banks are subject to regulation, as well as supervision, by the government. One form of regulation is deposit insurance. If a bank fails, the government (through a deposit insurance fund) ensures that no depositor suffers a loss as a consequence of this failure. That is, all deposits are fully insured. Equity holders, as residual claimants, are left with nothing in the event of failure. The rationale for the deposit insurance is left unmodeled. However, it can be argued that deposit insurance improves the ability of banks to create liquidity. ${ }^{4}$

Secondly, banks face a capital requirement, which requires them to have a minimum amount of equity as a fraction of (risk-weighted) assets. Since loans are the only type of asset in this model, the capital requirement simply states that equity needs be at least a fraction $\gamma$ of loans for a bank to be able to operate:

$$
E_{t} \geq \gamma L_{t}
$$

For the moment, the capital requirement is merely assumed. It will later be shown how it can be socially desirable to have such a requirement, as it mitigates the moral hazard problem that arises due to the presence of deposit insurance.

The bank can make loans to nonfinancial firms, described below. These loans are riskless ${ }^{5}$ and yield a rate of return $R_{t}^{L} . R_{t}^{L}$ is determined competitively in equilibrium, so each bank takes it as given. Thus, a bank that lends out $L_{t}$ units of the good at the beginning of the period will receive nonrandom total return of $R_{t}^{L} L_{t}$ units at the end of the period.

The presence of deposit insurance creates a moral hazard problem: the bank has an incentive to engage in excessive risk-taking. Since this is the justification for the capital requirement, I introduce a way for the bank to engage in excessive risk-taking by assuming that the bank has the option of artificially raising the riskiness of its assets. Specifically, by lending to a different set of

\footnotetext{
${ }^{4}$ Diamond and Dybvig (1983) provide a model of panic based bank runs, which can be seen as a rationale for deposit insurance.

${ }^{5}$ The assertion that the bank can make riskless loans is a consequence of the technology of the nonfinancial firms, as detailed below.
} 
nonfinancial firms with a risky technology, ${ }^{6}$ the bank can create a loan portfolio with riskiness $\sigma$ that pays off $R_{t}^{L}+\sigma_{t} \varepsilon_{t}$, where $\varepsilon_{t}$ is a bank-specific shock with the following distribution:

$$
\varepsilon_{t}=\left\{\begin{array}{cc}
1 & \text { with probability } 0.5 \\
-(1+2 \xi) & \text { with probability } 0.5
\end{array}\right.
$$

where $\xi$ is a positive constant. It is assumed that the bank can choose the riskiness of its loans, though there is an upper bound: $\sigma_{t} \in[0, \bar{\sigma}] .^{7}$ The variance of the return is $\sigma_{t}^{2}(1+\xi)^{2}$, which is increasing in $\sigma_{t}$, and its expected value is $R_{t}^{L}-\sigma_{t} \xi$, which is decreasing in $\sigma_{t}$. It is in this sense that risk-taking is excessive: absent a moral hazard problem due to deposit insurance, the bank would always choose $\sigma_{t}=0$.

I am now in a position to state the bank's problem. The objective of the bank is to maximize shareholder value by deciding how many loans to make, and how much risk to take on, and how to finance its assets with equity and deposits. Although the decision on how much equity to issue will be endogenized, it is convenient to first analyze the sub-problem of maximizing shareholder value right after the equity has been issued and the bank has raised $E_{t}$ in equity at the beginning of period $t$. At that point the value of the bank to its shareholders is: ${ }^{8}$

$$
\begin{gathered}
V^{B}(E)=\max _{L, D, \sigma} \mathbb{E}_{\varepsilon}\left[\left(\left(R^{L}+\sigma \varepsilon\right) L-R^{D} D\right)^{+}\right] / R^{E} \\
\text { s.t. } \quad L=E+D \\
E \geq \gamma L \\
\sigma \in[0, \bar{\sigma}]
\end{gathered}
$$

The notation $(x)^{+}$stands for $\max (x, 0)$ and $\mathbb{E}$ is the expectations operator. The first constraint is the balance sheet identity, the second is the capital requirement, and the third bounds $\sigma$.

The term $\left(R^{L}+\sigma \varepsilon\right) L-R^{D} D$ is the bank's net cash flow at the end of the period. It consists of interest income from loans, minus any possible charge-offs on the loans, and minus the interest owed to depositors. If the net cash-flow is positive, shareholders are paid the full amount in dividends. If the net cash flow is

\footnotetext{
${ }^{6}$ Again, the technology will be described below and will be consistent with the rates of return assumptions made here.

${ }^{7}$ The reason for the existence of an upper bound is provided in the discussion of the government.

${ }^{8}$ In what follows, time subscripts will be used only where necessary to avoid confusion.
} 
negative, the bank fails and the deposit insurance fund must cover the difference in order to indemnify depositors, as limited liability of shareholders rules out negative dividends. Shareholders receive zero in this event, so dividends equal $\left(\left(R^{L}+\sigma \varepsilon\right) L-R^{D} D\right)^{+}$.

At the beginning of period $t$ shareholders discount the value of dividends, which are paid at the end of that period, by their opportunity cost of holding this particular bank's equity. This opportunity cost is $R^{E}$, the market rate of return on equity. Because dividends are either not subject to risk, or, if $\sigma>0$, their risk is perfectly diversifiable, shareholders do not price the bank's risk. ${ }^{9}$

First, I characterize the choice of $\sigma$ conditional on $L$ and $D$. Note that

$$
\begin{aligned}
& \mathbb{E}_{\varepsilon}\left[\left(\left(R^{L}+\sigma \varepsilon\right) L-R^{D} D\right)^{+}\right] \\
& \quad=\left\{\begin{array}{cl}
\left(R^{L}-\sigma \xi\right) L-R^{D} D & \text { if }\left(R^{L}-\sigma(1+2 \xi)\right) L-R^{D} D \geq 0 \\
0.5\left(\left(R^{L}+\sigma\right) L-R^{D} D\right) & \text { otherwise }
\end{array}\right.
\end{aligned}
$$

Expected dividends are thus strictly decreasing in $\sigma$ for low values of $\sigma$ and strictly increasing in $\sigma$ for sufficiently high values of $\sigma .{ }^{10}$ The reason is that for high values of $\sigma$, if the bank suffers a negative shock, there is not enough equity to absorb the loss and the excess loss is covered by the deposit insurance fund. Increasing risk further at this point increases the payoff to shareholders in the good state $(\varepsilon=1)$ without lowering it in the bad state. In other words, the value of the put option associated with the deposit insurance fund increases with $\sigma$. In contrast, when $\sigma$ is low, the value of this put option is zero and shareholders fully take into account the reduction in net present value that occurs when risk is increased.

Because expected dividends are a convex function of $\sigma$, there are only two values to consider for the optimal choice of riskiness: $\sigma=0$ or $\sigma=\bar{\sigma}$. It is easy to show that

$$
\begin{aligned}
& \sigma=0 \text { iff } \bar{\sigma} \leq R^{L}-R^{D}(D / L) \\
& \sigma=\bar{\sigma} \text { otherwise }
\end{aligned}
$$

\footnotetext{
${ }^{9}$ Hence, the treatment of $R^{E}$ as nonstochastic in the household problem is still correct, since, even if banks are risky, households would not leave any such risk undiversified.

${ }^{10}$ Note that there is no discontinuity at $\left(R^{L}-\sigma(1+2 \xi)\right) L-R^{D} D=0$.

${ }^{11}$ When $\bar{\sigma}=R^{L}-R^{D}(D / L)$, the bank is indifferent between the two choices. For convenience, it is assumed that the bank chooses $\sigma=0$ in that case.
} 
Because $E=L-D \geq \gamma L$, the following is a sufficient condition for $\sigma=0$ :

$$
\bar{\sigma} \leq R^{L}-R^{D}(1-\gamma)
$$

This is also a necessary condition when the capital requirement is binding. From now on, unless explicitly stated otherwise, it is assumed that (6) holds.

The bank's sub-problem in (5) now simplifies to:

$$
\begin{gathered}
V^{B}(E)=\max _{L, D}\left(R^{L} L-R^{D} D\right) / R^{E} \\
\text { s.t. } \quad L-D=E \\
\quad E-\gamma L \geq 0
\end{gathered}
$$

The first-order conditions are easily simplified to

$$
R^{L}-R^{D}=\gamma R^{E} \chi
$$

where $\chi$ is the Kuhn-Tucker multiplier associated with the capital requirement: $\chi \geq 0$ and $\chi(E-\gamma L)=0$. The existence of a (finite) solution requires $R^{L} \geq R^{D}$. Under that condition, the solution is

$$
V^{B}(E)=\left(R^{L}+\left(\gamma^{-1}-1\right)\left(R^{L}-R^{D}\right)\right) E / R^{E}
$$

The capital requirement binds if and only if $R^{L}>R^{D}$. The interpretation is straightforward: an extra unit of equity can be lent out at the rate $R^{L}$. In addition, the extra unit of capital allows the bank to make $\left(\gamma^{-1}-1\right)$ additional loans and finance those with deposits, without violating the capital requirement, which requires $L \leq \gamma^{-1} E$. If $R^{L}>R^{D}$, the second option has value, and the capital requirement will be binding, otherwise not.

I can now turn to the bank's decision on how much equity to raise. The pre-issue value of the bank is $V^{B}(E)-E$. The bank maximizes this value when choosing $E$ :

$$
\begin{aligned}
\pi^{B} & =\max _{E}\left(V^{B}(E)-E\right) \\
& =\max _{E}\left(R^{L}+\left(\gamma^{-1}-1\right)\left(R^{L}-R^{D}\right)\right) E / R^{E}-E
\end{aligned}
$$


The first-order condition is: ${ }^{12}$

$$
R^{E}=R^{L}+\left(\gamma^{-1}-1\right)\left(R^{L}-R^{D}\right)
$$

Since we have already established that $R^{L} \geq R^{D}$ is necessary for a solution to exist and that the capital requirement binds if and only if $R^{L}>R^{D}$, we can distinguish two cases:

1. If $R^{L}=R^{D}$, the capital requirement is slack and

$$
R^{E}=R^{L}=R^{D}
$$

2. If $R^{L}>R^{D}$, the capital requirement is binding, so $E=\gamma L$, and

$$
R^{L}=(1-\gamma) R^{D}+\gamma R^{E}
$$

In either case, $V^{B}(E)-E=0$.

In the case of a binding capital requirement, one unit of lending is financed by $\gamma$ in equity and $(1-\gamma)$ in deposits, so for zero profits the rate of return to lending better equal the similarly weighted average of the required rates of return of equity and deposits, which is what is stated in (9).

Note that the sufficient condition for $\sigma=0$ to be optimal, given in (6), is seen to be equivalent to

$$
\bar{\sigma} \leq \gamma R^{E}
$$

Again, this condition is also necessary if the capital requirement is binding.

Firms: Nonfinancial firms cannot create liquidity through deposits. They can, however, buy goods to use them as capital, which can be combined with labor input, to produce output of the good. Capital is purchased at the beginning of the period. To finance their capital stock, firms can issue equity to households,

\footnotetext{
${ }^{12}$ As is common in problems with constant returns to scale, the first order condition, rather than fully determining the agent's choice, has the interpretation of a necessary condition for the existence of a finite solution. If $R^{E}<(>) R^{L}+\left(\gamma^{-1}-1\right)\left(R^{L}-R^{D}\right)$, then $E$ tends to plus (minus) infinity. If the first-order condition holds, $E$ is indeterminate, and thus so is the scale of the bank.
} 
borrow from banks, or some combination of both. The firm's balance sheet, and notation, for period $t$ is:

\begin{tabular}{ll|ll}
\multicolumn{2}{l}{ Assets } & \multicolumn{2}{c}{ Liabilities } \\
\hline$K_{t} \quad$ Physical Capital & $L_{t}$ & Loans \\
& $E_{t}^{F}$ & Firm Equity
\end{tabular}

There is a continuum of firms with mass normalized to one. Firms can employ a riskless or a risky production technology. The riskless technology is standard. ${ }^{13}$ Output in period $t$ is $F\left(K_{t}, H_{t}\right)$, where $H_{t}$ is hours of labor input and $F()$ is a well-behaved production function exhibiting constant returns to scale. A fraction $\delta$ of the capital stock depreciates during the period. There are no adjustment costs. The absence of adjustment costs implies that firm's problem is static.

As in the analysis of the bank's problem, it is convenient to start with the firm's decision problem right after it has raised $E_{t}^{F}$ in equity. At that point the value of the firm to its shareholders is

$$
V^{F}\left(E^{F}\right)=\max _{K, H}\left(F(K, H)+(1-\delta) K-w H-R^{L}\left(K-E^{F}\right)\right) / R^{E}
$$

Here I have substituted out loans using the balance sheet identity. ${ }^{14}$ The first-order conditions for the choices of capital and labor inputs are standard:

(H) $\quad F_{H}(K, H)=w$

$(K) \quad F_{K}(K, H)+(1-\delta)=R^{L}$

These optimality conditions, together with the constant returns to scale assumption, imply that the solution for the firm's shareholder value is: $V^{F}\left(E^{F}\right)=\left(R^{L} E^{F}\right) / R^{E}$. The pre-issue value of the firm is $V^{F}\left(E^{F}\right)-E^{F}$. The firm maximizes this value when choosing $E^{F}$. It is assumed that equity cannot be negative.

\footnotetext{
${ }^{13}$ It would be straightforward to let both types of firms have risky production, and therefore, risky loans to individual firms even while keeping $\sigma=0$ as feasible for banks, as long as the production shocks are sufficiently imperfectly correlated across firms, so that the risk is perfectly diversifiable by lending to many firms. Excessive risk taking would then correspond to not diversifying this risk.

${ }^{14}$ Note that the absence of arbitrage opportunities implies that nonfinancial firms have to offer shareholders the same return on equity as banks, since there is no aggregate risk.
} 


$$
\pi^{F}=\max _{E^{F} \geq 0} V^{F}\left(E^{F}\right)-E^{F}
$$

The first order condition is

$\left(E^{F}\right) \quad R^{E}=R^{L}+\mu$

where $\mu$ is the Kuhn-Tucker multiplier associated with the constraint that firm equity cannot be less than zero $\left(\mu \geq 0, \mu E^{F}=0\right) .{ }^{15} \mathrm{~A}$ finite solution requires $R^{L} \leq R^{E}$.

If $R^{L}<R^{E}$, then $E^{F}=0$, so $K=L$. In other words, if bank loans are cheaper than equity finance, the firm chooses to use only bank loans to finance its capital. If $R^{E}=R^{L}$, the firm's financial structure is not determined by individual optimality. In either case economic profits, $\pi^{F}$, equal zero.

Which case applies turns out to depend on whether or not the demand for liquidity is satiated. To see this, recall that the analysis of the household's problem established that the required rate of return for risk-free equity is higher than the required rate of return for bank deposits: $R^{D} \leq R^{E}$ (see equations (2) and (3)). Moreover, the inequality is strict if and only if the households' demand for liquidity is nonsatiated. From the bank's problem we know that $R^{L}=(1-\gamma) R^{D}+\gamma R^{E} \cdot{ }^{16}$ It follows that, in fact,

$$
R^{L} \leq R^{E}
$$

and that this inequality is strict if and only if the households' demand for liquidity is nonsatiated.

Hence, as long as liquidity preference is not satiated, nonfinancial firms finance all their capital stock with the cheaper bank loans, rather than equity. ${ }^{17}$ If instead the demand for liquidity is satiated $\left(u_{d}(c, d)=0\right)$, firms are indifferent between the two forms of finance. For this less interesting case, I assume without loss of generality that firms still opt for bank loans only. ${ }^{18}$

\footnotetext{
${ }^{15}$ Technically, $\mu$ is the multiplier to that constraint after rescaling the problem by $R^{E}$, a constant to the firm.

${ }^{16}$ Note that this is true whether the capital requirement slack or binding.

${ }^{17}$ With the risk free technology there are no costs of bankruptcy or financial distress.

${ }^{18}$ This assumption is made for convenience and is without loss of generality in the sense that it has no effect on the model's predictions for any equilibrium rates of return or the paths of consumption and capital accumulation.
} 
In addition to this riskless technology, firms can also employ a risky technology. Risky firms provide a vehicle for banks to make the kind of risky loans described in the subsection on banks. Although these firms thus provide a rationale for the existence of capital regulation, as mentioned, I will usually focus on the case that the capital requirement is sufficiently high, according to condition (10), to prevent banks from engaging in excessive risk taking. These risky firms will then not exist in equilibrium. For this reason analysis of these firms is left for appendix A. Here I simply state the assumptions regarding the risky technology.

Risky firms differ in that their output is subject to an additive shock that is proportional to their capital stock: output is $F(K, H)+\sigma_{R F} \varepsilon K$, where $\varepsilon$ is the same negative mean shock as defined in (4) and $\sigma_{R F}$ is a parameter $\left(\sigma_{R F} \geq \bar{\sigma}\right)$. The choice of technology (i.e. the type of firm) is observable to all parties to a financial contract with the firm, so there is no asymmetric information. It is straightforward to verify that no household is willing to provide the risky firm with equity. The appendix shows how the optimal loan contract with such a firm gives banks the ability to create a risky loan portfolio as described in the subsection on banks. A loan portfolio with riskiness $\sigma$ is created by directing a fraction $\sigma / \sigma_{R F}$ of lending to risky firms with perfectly correlated shocks (e.g. by lending to one risky firm).

Government: The government manages the deposit insurance fund, sets a capital requirement $\gamma \in[0,1)$ and conducts bank supervision. Bank supervision is necessary to enforce the capital requirement. A second role for bank supervision is to control excessive risk taking by banks. Supervisors can to some degree detect such behavior and stop any bank that is 'caught' attempting to take on excessive risk in order to protect the deposit insurance fund. It seems reasonable to assume that a small amount of risk taking is harder to detect than a large amount. The largest level of risk-taking that is still just undetectable is $\bar{\sigma} . \bar{\sigma}$ is assumed to be a decreasing function of the resources devoted to bank supervision:

$$
\bar{\sigma}=S(T) \text { with } S^{\prime}(\bullet) \leq 0 \text { and } 0<S \leq \sigma_{R F}
$$

where $T$, a choice variable for the government, is the part of tax revenue spent on bank supervision. ${ }^{19}$ The interpretation is that, as more resources are devoted to

\footnotetext{
${ }^{19}$ As in the standard growth model with government spending and lump sum taxes, if $T$ is set 'too high', no equilibrium with positive consumption will exist. I assume that $T$ is sufficiently low so
} 
bank supervision, banks are less able to engage in excessive risk taking without being detected.

The government has a balanced budget. Lump-sum taxes are set at

$$
T_{t}=T+0.5\left(R_{t}^{D} D_{t}-\left(R_{t}^{L}-\sigma_{t}(1+2 \xi)\right) L_{t}\right)^{+} .
$$

The second term represents the cost reimbursing depositors of failed banks under the deposit insurance scheme. $\sigma_{t}=0$ or $\sigma_{t}=\bar{\sigma}$ depending on the banks' choice. If (10) holds, we know that $\sigma_{t}=0$ and in that case taxes are simply: $T_{t}=T$.

\section{General Equilibrium}

Given a government policy $\gamma$ and $T$, an equilibrium is defined as a path of consumption, capital, deposits, equity holdings, bank loans and financial returns, for $t=0,1,2, \ldots$ such that:

1. Households, banks and nonfinancial firms all solve their maximization problems, described above, with taxes set according to (13);

2. All markets clear, i.e.

$$
\begin{aligned}
& d_{t}=D_{t} \\
& e_{t}=E_{t} \\
& K_{t}=L_{t} \\
& H_{t}=1
\end{aligned}
$$

and

$$
F\left(K_{t}, 1\right)-\sigma_{t} \xi K_{t}+(1-\delta) K_{t}=c_{t}+K_{t+1}+T ;
$$

I focus on the case that (10) holds: $S(T) \leq \gamma R_{t}^{E}$. Government policy can accomplish this by setting $\gamma$ and/or $T$ sufficiently high. In that case, $\sigma_{t}=0$ and $T_{t}=T$. Combining the market clearing conditions and equations (2), (3), (8), (9), (11), and (12), it is possible to characterize the equilibrium in terms of a system in $\left(K_{t}, c_{t}\right)$ with $R_{t}^{E}$ and $d_{t}$ as auxiliary variables, by distinguishing two cases, depending on whether the capital requirement binds in period $t$ :

Case 1: If $u_{d}\left(c_{t},(1-\gamma) K_{t}\right)=0$, the capital requirement is not binding and

that a steady state equilibrium with positive consumption exists. Appendix B makes precise what 'sufficiently low' means for particular functional form of the utility function. 


$$
\begin{aligned}
& \beta^{-1}\left(u_{c}\left(c_{t-1}, d_{t-1}\right) / u_{c}\left(c_{t}, d_{t}\right)\right)=R_{t}^{E} \\
& F_{K}\left(K_{t}, 1\right)+1-\delta=R_{t}^{E} \\
& d_{t} \leq(1-\gamma) K_{t} \text { and } u_{d}\left(c_{t}, d_{t}\right)=0 \\
& K_{t+1}=F\left(K_{t}, 1\right)+(1-\delta) K_{t}-c_{t}-T
\end{aligned}
$$

Remark: this requires that demand for liquidity be satiated at $d=(1-\gamma) K_{t} . d_{t}$ and $e_{t}$ are not determined except in that $d_{t} \leq(1-\gamma) K_{t}$ and $e_{t}=K_{t}-d_{t} . L_{t}=K_{t}$ and $R_{t}^{L}=R_{t}^{D}=R_{t}^{E}$. The real wage is determined through (11) with $H_{t}=1$. Note that with $u_{d}\left(c_{t}, d_{t}\right)=0, u_{c}\left(c_{t}, d_{t}\right)$ does not depend on $d_{t}$.

Case 2: If $u_{d}\left(c_{t},(1-\gamma) K_{t}\right)>0$, the capital requirement is binding and

$$
\begin{aligned}
& \beta^{-1}\left(u_{c}\left(c_{t-1}, d_{t-1}\right) / u_{c}\left(c_{t}, d_{t}\right)\right)=R_{t}^{E} \\
& \begin{aligned}
F_{K}\left(K_{t}, 1\right)+1-\delta & =(1-\gamma) R_{t}^{D}+\gamma R_{t}^{E} \\
& =R_{t}^{E}-(1-\gamma) \frac{u_{d}\left(c_{t}, d_{t}\right)}{u_{c}\left(c_{t}, d_{t}\right)}
\end{aligned} \\
& d_{t}=(1-\gamma) K_{t} \\
& K_{t+1}=F\left(K_{t}, 1\right)+(1-\delta) K_{t}-c_{t}-T
\end{aligned}
$$

Remark: $L_{t}=K_{t}$ and remaining variables are determined through (3), (9) and (11) with $H_{t}=1$.

In the first case, the capital requirement is nonbinding, because the level of deposits is such that the marginal value of liquidity provision is zero, which implies that their rate of return is no different from equity: $R_{t}^{D}=R_{t}^{E}$. Except for the lump sum taxes, there is no material difference here with a standard growth model. Banks channel funds from households to firms, but they do not really matter at the margin, since their special ability to create liquidity has no marginal value $\left(R_{t}^{L}=R_{t}^{E}\right)$.

In the second case, the pecuniary return on deposits is lower than the return on equity by a spread equal to $u_{d}\left(c_{t}, d_{t}\right) / u_{c}\left(c_{t}, d_{t}\right)$, which is the marginal value of deposits' liquidity services expressed in units of consumption. The capital requirement is now binding, since banks want to fund their assets as much as possible with the cheaper deposits. Because banking is characterized by perfect 
competition, banks fully pass on the lower cost of funding their loans to their borrowers, firms. However, since banks still have to finance a fraction $\gamma$ of their lending with equity, the loan rate declines only by $(1-\gamma)\left(u_{d}\left(c_{t}, d_{t}\right) / u_{c}\left(c_{t}, d_{t}\right)\right)$.

\section{A steady state result: No superneutrality}

Because banks pass on the low pecuniary return on deposits to their borrowers, the steady state level of the capital stock is not generally invariant to capital adequacy regulation. This contrasts with the superneutrality result of the Sidrauski (1967) model. ${ }^{20}$ In the present model, raising $\gamma$ can increase or lower the steady state capital stock, depending on the interest elasticity of liquidity demand. For example, suppose that

$$
u(c, d)=\tilde{u}(\phi(c, d)) \text { and } \phi(c, d)=\left\{c^{(\eta-1) / \eta}+a d^{(\eta-1) / \eta}\right\}^{\eta /(\eta-1)}
$$

with $a, \eta>0, \tilde{u}^{\prime}>0$ and $\tilde{u}^{\prime \prime}<0$. Then

$$
\frac{u_{d}\left(c_{t}, d_{t}\right)}{u_{c}\left(c_{t}, d_{t}\right)}=a\left(\frac{d_{t}}{c_{t}}\right)^{-1 / \eta},
$$

so that demand for deposits is given by

$$
d_{t}=a^{\eta} c_{t}\left(R_{t}^{E}-R_{t}^{D}\right)^{-\eta} .
$$

Hence, $\eta$ has the interpretation of the interest elasticity of the demand for deposits. It is straightforward to show that for this specification, the steady state level of the capital stock, $K^{*}$, is increasing (decreasing) in $\gamma$ if $0<\eta<1 \quad(\eta>1)$. A proof can be found in Appendix B. ${ }^{21}$

The intuition for this result is as follows. Firms set the marginal product of capital equal to the rate on bank loans, which in turn equals

$$
R^{L}=R^{E}-(1-\gamma)\left(R^{E}-R^{D}\right)
$$

\footnotetext{
${ }^{20}$ In the Sidrauski model, the rate of inflation (which is what determines the rate of return on monetary assets) has no impact on the steady state capital stock. The reason is that in that model money is created by a monopolistic entity, the government, which does not in any way use the revenues from liquidity creation (seignorage) to lower the marginal cost of funding investment. ${ }^{21}$ The proof in Appendix B makes explicit the assumption that taxes $T$ are sufficiently low to guarantee the existence of a steady state equilibrium with positive consumption. See footnote 19.
} 
(cf. (9)). In steady state, $R^{E}=\beta^{-1}$. An increase in $\gamma$ has two effects on $R^{L}$ : one is to force banks to rely more on equity finance, which is more expensive than deposits $\left(R^{E}-R^{D}>0\right)$. This effect, which is explicit in the above equation, increases $R^{L}$. The second effect is a general equilibrium feedback. The fact that bank must rely less on deposits makes them more scarce to households, which increases the spread $R^{E}-R^{D}$. This second effect lowers the competitive rate on bank loans. If the interest elasticity of the demand for deposits is low $(0<\eta<1)$, a large increase in the spread will be necessary to convince households to make do with fewer deposits, and the second effect will dominate. In that case, $R^{L}$ falls and the steady state level of capital thus rises, otherwise not.

A related point is that the steady state level of the capital stock depends on the strength of the preference for liquidity. Without any preference for liquidity, equity, deposits and bank loans all command the same return, equal to $\beta^{-1}$ in steady state. In the above example, this occurs when $a=0$. On the other hand, if liquidity has value ( $a>0$ in the example), the steady state return on equity will still be $\beta^{-1}$, but the return on deposits, and therefore the return on bank loans, will be strictly lower than that. Since firms equate the marginal product of capital to the rate on bank loans, it follows that the steady state capital stock is higher when households exhibit a preference for liquidity.

\section{The welfare cost of the capital requirement: a first-order approximation}

The strategy for quantifying the welfare cost of the capital requirement is as follows. First, I present the constrained social planner's problem to the model. The qualification 'constrained' means that the social planner's problem shall respect the capital requirement and devote the same level of resources to supervision. This will ensure that the allocation that solves the social planner's problem is incentive compatible for the banks. I then show that the allocation associated with the social planner's problem is identical to the allocation of the decentralized equilibrium described above. Finally, I use this equivalence to derive analytically a first-order approximation of the welfare cost of increasing the capital requirement $\gamma$. 


\section{The social planner's problem}

Define the following constrained social planner's problem:

$$
\begin{gathered}
V_{0}(\theta)=\max _{\left\{c_{t}, d_{t}, K_{t+1}\right\}_{t=0}^{\infty}} \sum_{t=0}^{\infty} \beta^{t} u\left(c_{t}, d_{t}\right) \\
\text { s.t. } \quad F\left(K_{t}, 1\right)+(1-\delta) K_{t}=c_{t}+K_{t+1}+T \\
(1-\gamma) K_{t}-d_{t} \geq 0
\end{gathered}
$$

where $\theta=\left(\gamma, T, \delta, \beta, K_{0}\right)$. The first constraint is the social resource constraint for $\sigma=0 ;^{22}$ the second constraint rewrites the capital requirement. The Lagrangian and the first-order conditions to this problem are:

$$
\begin{gathered}
\ell_{0}(\theta)=\max _{\left\{c_{t}, d_{t}, K_{t+1}\right\}_{t=0}^{\infty}} \sum_{t=0}^{\infty} \beta^{t}\left\{u\left(c_{t}, d_{t}\right)+\lambda_{t}^{s p}\left[F\left(K_{t}, 1\right)+(1-\delta) K_{t}-c_{t}-K_{t+1}-T\right]\right. \\
\left.+\chi_{t}^{s p}\left[(1-\gamma) K_{t}-d_{t}\right]\right\}
\end{gathered}
$$

$$
u_{c}\left(c_{t}, d_{t}\right)=\lambda_{t}^{s p}
$$

$$
u_{d}\left(c_{t}, d_{t}\right)=\chi_{t}^{s p}
$$

$$
\lambda_{t}^{s p}\left[F_{K}\left(K_{t}, 1\right)+1-\delta\right]-\beta^{-1} \lambda_{t-1}^{s p}+\chi_{t}^{s p}(1-\gamma)=0
$$

Combing these first-order conditions yields:

$$
F_{K}\left(K_{t}, 1\right)+1-\delta=\left(\frac{\beta^{-1} u_{c}\left(c_{t-1}, d_{t-1}\right)}{u_{c}\left(c_{t}, d_{t}\right)}\right)-(1-\gamma)\left(\frac{u_{d}\left(c_{t}, d_{t}\right)}{u_{c}\left(c_{t}, d_{t}\right)}\right)
$$

In addition, since $u_{d d}(c, d) \leq 0$ by concavity of $u$, the first order condition with respect to deposits, combined with the complementary slackness conditions $d_{t} \leq(1-\gamma) K_{t}, \chi_{t}^{s p} \geq 0$ and $\chi_{t}^{s p}\left((1-\gamma) K_{t}-d_{t}\right)=0$, implies :

$$
\begin{aligned}
& \text { if } u_{d}\left(c_{t},(1-\gamma) K_{t}\right)=0 \text { then } d_{t} \leq(1-\gamma) K_{t} \text {, with } u_{d}\left(c_{t}, d_{t}\right)=0 \text {; } \\
& \text { if } u_{d}\left(c_{t},(1-\gamma) K_{t}\right)>0 \text { then } d_{t}=(1-\gamma) K_{t}
\end{aligned}
$$

\footnotetext{
${ }^{22}$ The absence of excessive risk taking is simply part of the definition of the constrained social planner's problem.
} 
Combining equations (17), (18) and (19) with the social resource constraint (the first constraint to the problem in (16)), it is apparent that the allocations of $K_{t}, c_{t}$ and $d_{t}$ are identical to those of the decentralized equilibrium summarized above in the systems of equations (14) and (15). Equation (18) corresponds to an equilibrium with a nonbinding capital requirement ('case 1', system (14)), while equation (19) corresponds to the case of a binding capital requirement ('case 2', system (15)).

Hence, the constrained social planner's problem replicates the decentralized equilibrium when $\sigma=0$ in the decentralized equilibrium. As a result, if $\sigma=0$, welfare in the decentralized equilibrium is equal to $V_{0}(\theta)$, the value of the objective function to the constrained social planner's problem.

\section{A formula for the marginal welfare cost}

The equivalence of the constrained social planner's problem and the decentralized equilibrium can be used to measure the marginal effect on welfare of a change in the capital requirement in the following way. Call the current period period 0. Assume government policy is such that (10) holds: $S(T) \leq \gamma R_{t}^{E}$ for all $t \geq 0$, so that $\sigma_{t}=0$ in the decentralized equilibrium. That is, the capital requirement is sufficiently high to be successful in preventing excessive risk taking. Starting from this situation, I compute the marginal effect on welfare of raising $\gamma$, without altering $T$, using the envelope theorem, as follows:

$$
\frac{\partial V_{0}(\theta)}{\partial \gamma}=\frac{\partial \ell_{0}(\theta)}{\partial \gamma}=-\sum_{t=0}^{\infty} \beta^{t} \chi_{t}^{s p} K_{t}=-\sum_{t=0}^{\infty} \beta^{t} u_{d}\left(c_{t}, d_{t}\right) K_{t}
$$

The last equality follows from the first order condition $(d)$ to the social planner's problem. Since the allocations of $K_{t}, c_{t}$ and $d_{t}$ are identical to those of the decentralized equilibrium, I can use the decentralized equilibrium values for the variables on the right hand side of this equation. Moreover, in the decentralized equilibrium, we have, using (3),

$$
\begin{aligned}
u_{d}\left(c_{t}, d_{t}\right) K_{t} & =u_{c}\left(c_{t}, d_{t}\right)\left(R_{t}^{E}-R_{t}^{D}\right) K_{t} \\
& =u_{c}\left(c_{t}, d_{t}\right)\left(R_{t}^{E}-R_{t}^{D}\right) d_{t} /(1-\gamma)
\end{aligned}
$$


where the last equality follows from the fact that $d_{t}=(1-\gamma) K_{t}$ if the capital requirement binds, and that $\left(R_{t}^{E}-R_{t}^{D}\right)=0$ if it does not bind.

I compare this to the welfare effect of a permanent change in consumption by a factor $(1+v)$. Starting from the initial equilibrium, the effect on welfare of changing consumption from $c_{t}$ to $(1+v) c_{t}$, for all $t$, equals to a first-order approximation,

$$
\left(\sum_{t=0}^{\infty} \beta^{t} u_{c}\left(c_{t}, d_{t}\right) c_{t}\right) v
$$

Next, let's assume that the economy is in steady state in period 0 . Then the first order approximation of the welfare effect of an increase in $\gamma$ by $\Delta \gamma$ simplifies as follows:

$$
\frac{\partial V_{0}(\theta)}{\partial \gamma} \Delta \gamma=-\frac{u_{d}\left(c_{0}, d_{0}\right) K_{0}}{1-\beta} \Delta \gamma=-\frac{u_{c}\left(c_{0}, d_{0}\right)\left(R_{0}^{E}-R_{0}^{D}\right) d_{0}}{(1-\beta)(1-\gamma)} \Delta \gamma
$$

while

$$
\left(\sum_{t=0}^{\infty} \beta^{t} u_{c}\left(c_{t}, d_{t}\right) c_{t}\right) v=\left(\frac{u_{c}\left(c_{0}, d_{0}\right) c_{0}}{1-\beta}\right) v
$$

if period 0 is a steady state. Equating the right hand sides of these last two equations, we have the following result. ${ }^{23}$

Proposition 1: Assume the economy is in steady state in period 0 and (10) holds. Consider permanently increasing $\gamma$ by $\Delta \gamma$. A first-order approximation to the resulting welfare loss, expressed as the welfare-equivalent permanent relative loss in consumption, is

$$
\nu(\Delta \gamma)=\frac{d_{0}}{c_{0}}\left(R_{0}^{E}-R_{0}^{D}\right)(1-\gamma)^{-1} \Delta \gamma
$$

\footnotetext{
${ }^{23}$ Equate the right hand sides of these two equations to solve for $v$. With $\Delta \gamma>0$, the result is a negative value for $v$ which, to a first-order approximation, consumers would be equally unhappy to experience as a rise in the capital requirement by $\Delta \gamma \cdot v(\Delta \gamma)$ in the proposition is the absolute value of this negative value, which is thus the first-order approximate welfare-equivalent relative loss in consumption associated with $\Delta \gamma$.
} 
The above formula is, at least in principle, empirically implementable. Remarkably, it does not rely on any assumptions about the functional form of preferences, beyond the standard assumptions of monotinicity, differentiability and concavity. Instead, the formula relies on asset returns to reveal the representative household's preference for liquidity relative to consumption. An unnecessary increase in the capital requirement reduces welfare by reducing the ability of banks to issue deposit-type liabilities for any given level of bank assets.

The first factor in the formula for the welfare loss concerns the importance of deposits in the economy. The second is the spread between the return on bank equity and the pecuniary return to deposits. This spread equals the amount of consumption households are willing to forgo in order to enjoy the liquidity services of one additional unit of deposits. Finally, $(1-\gamma)^{-1} \Delta \gamma$ is the relative change in deposits as a result of changing the capital requirement for a given level of bank assets.

Note that, while the proposition assumes that the economy is initially in steady state, the welfare loss takes into account, to a first-order approximation, all the gains or losses associated with the transition to a new steady state upon changing the capital requirement.

It may still seem surprising that no assumptions were needed on functional form the utility function. After all, to use the Sidrauski model to measure the welfare cost of inflation, as in Lucas (2000), one does need to specify the functional form of the utility function. The difference is that, while money in the Sidrauski model is created by a nonoptimizing monopolist (the government), in this model the supply of liquidity is created by competitive banks. This additional structure in the model means we have some information on how the quantity of deposits will change as we change the capital requirement. In contrast, in the Sidrauski model, to know the change in real balances in response to a change in inflation, one needs to know the interest elasticity of money demand, which amounts to requiring more knowledge of the utility function.

\section{Measurement of the welfare cost}

The main result so far is an expression for the welfare cost of a bank capital requirement. The expression lends itself to a calculation of this cost based on data. The data used here are annual aggregate balance sheet and income 
statement data for all FDIC-Insured Commercial Banks in the United States (50 states and DC), obtained from the FDIC's Historical Statistics on Banking (HSOB). These data are based on regulatory filings.

In mapping the theory to the data, some choices need to be made. For deposits, $D(=d)$, the HSOB's Total Deposits is used. ${ }^{24}$ The net return on deposits $\left(R^{D}-1\right)$ is calculated as Interest on Total Deposits divided by Total Deposits. For consumption, $c$, I use personal consumption expenditures from the NIPA. As a measure of the capital requirement $\gamma$ the empirical counterpart of $E / L$ is used. ${ }^{25}$ This is computed as Total Equity Capital plus Subordinated Notes divided by Total Assets. Subordinated Notes are included because subordinated debt counts, within certain limits, towards regulatory tier 2 capital. Total Equity Capital plus Subordinated Notes does not exactly correspond to total capital in the sense of the Basle Accord, on which current capital adequacy regulation in the US (and many other countries) is based. However, data on total capital in the sense of the Basle Accord is only available starting in 1996 and it seems more important to be able to use a longer time span, especially since the formula for the marginal welfare cost in (21) is not very sensitive to the measurement of $\gamma$.

An alternative would have been to use the actual regulatory numbers for the capital requirement (either 0.08 for total capital based on the Basle Accord or 0.10 based on the FDICIA, the CAMELS ratings and the Gramm-Leach-Bliley Act). However, both the data and theory ${ }^{26}$ suggest that the vast majority of banks hold a buffer of equity above the regulatory minimum so as to lower the risk of an adverse shock leading to capital inadequacy. Since the model abstracts from this buffer stock behavior by assuming away any shocks, one would want to include this buffer in the measurement of $\gamma$ as it is due to the capital adequacy regulation in the first place. ${ }^{27}$ There is little reason to expect the buffer itself would change dramatically in response to a change in the regulatory minimum capital ratio. In any case, as mentioned, the point is not quantitatively very important. For example, as we change the measure of $\gamma$ from an unreasonably low value, say, 0.04 to an unreasonably high value, say 0.15 , holding constant the other

\footnotetext{
${ }^{24}$ All variables are nominal. While the model is real, using nominal data is fine, as long as all data are nominal, because the formula for the welfare cost in (21) contains only ratios of quantities and spreads of returns.

${ }^{25}$ This may seem incorrect if the capital requirement is not binding. However, if that is the case, the model implies that $R^{E}=R^{D}$, so the welfare cost is zero regardless of how $\gamma$ is measured.

${ }^{26}$ See Van den Heuvel (2004) for a quantitative model.

${ }^{27}$ In addition these ratios apply to risk weighted assets and off-balance sheet items, considerations from which the model also abstracts.
} 
measurements, the estimated marginal welfare cost increases only by a factor 1.13 $\left(=(1-0.15)^{-1} /(1-0.04)^{-1}\right)$.

Finally, a measure of the required return on (bank) equity is needed. Since the model abstracts from aggregate risk, a risk-adjusted measure is needed. To avoid the difficulties inherent in measuring the (ex ante) risk premium on regular equity, ${ }^{28}$ the measure I use is the average return on subordinated bank debt. The reason for this choice is that (a) subordinated debt counts towards regulatory equity capital, albeit within certain limits, and (b) defaults on this type of debt have historically been very rare, so the debt is not very risky. As a measure for $\left(R^{E}-1\right)$, the net return on subordinated debt is calculated as Interest on Subordinated Notes and Debentures divided by Subordinated Notes and Debentures. $^{29}$

The limits on the use of subordinated debt for regulatory purposes imply that this is a conservative measure for the risk-adjusted required return on bank equity. First, because it is regarded as an inferior form of equity, subordinated debt can count only towards tier 2 capital. Second, and more importantly, the amount of subordinated debt is limited to 50 percent of the bank's tier 1 capital. What this means is that if the tier 1 capital ratio is close to binding, subordinated debt can count for at most approximately 25 percent of total capital. Since banks may use subordinated debt to meet their capital requirements only up to these limits (and they do not have to use it), it is possible that for many banks the required return on subordinated debt is lower than the risk-adjusted return on regular equity.

To measure the welfare cost using the derived formula I compute long run averages for the deposit consumption ratio, for the spread between the return on subordinated debt and deposits, and for the capital asset ratio. The Basle Accord and the FDIC Improvement Act enacting it were not fully implemented until January 1, 1993. For this reason, the sample period is set at 1993-2002. Using

\footnotetext{
${ }^{28}$ For example, the historical average excess return on bank equity would imply a high premium, but does this equal the ex ante expected premium? In addition, depending on what interest rate is used to measure the excess return on equity, this approach runs the risk of contaminating the measured risk premium with a liquidity premium, which one would definitely want to avoid in the present context. If on the other hand one takes a model based measure of the ex ante risk premium based on 'reasonable' preferences, one would likely get a much lower measure. (This is the well known equity premium puzzle.)

${ }^{29}$ A part of what is counted in the HSOB as Subordinated Debt and Debentures does not qualify as regulatory tier 2 capital (e.g. if the maturity is too short). However, cross-checking with the Reports on Condition and Income ('call reports') item RCFD5610 indicates that the difference is minimal after 1992.
} 
1986-2002 as a longer sample yields very similar results. (1986 is the first year that regulation $\mathrm{Q}$ is fully phased out.)

For 1993-2002 the mean deposit to consumption ratio is 0.61 , the average net returns on deposits and subordinated debts are, respectively, 3.08\% and $6.26 \%$, so the average spread is $3.18 \%$, and the mean capital asset ratio is 0.096 . Hence, applying (21), a first order approximation to the welfare cost of raising the capital requirement by $\Delta \gamma$ is:

$$
v(\Delta \gamma)=0.61 \times 0.0318 \times(1-0.096)^{-1} \Delta \gamma=0.0216 \Delta \gamma
$$

To interpret this number, suppose that new regulation increases $\gamma$ by 0.1 (approximately a doubling of the effective capital requirement) without any change in bank supervision. The resulting welfare loss is equivalent to a permanent loss in consumption of $v(0.1)=0.0216 \times 0.1 \times 100 \%=0.216 \%$. This is

not, in my view, a trivial welfare cost. Some well-known estimates on the welfare costs of business cycles or the welfare gains of implementing the optimal monetary policy rule (taking as given average inflation) are much smaller.

One objection one might have to the above calculation of the welfare cost is that it does not take into account resource costs that banks incur in servicing deposits or making loans. The former include the costs of ATM networks, part of the cost of maintaining a network of branches, etc. The latter include the costs of screening loan applications, collecting payments, as well as part of the cost of maintaining a branch network. These costs are not trivial. For the period 19932002 net noninterest cost of U.S. banks have averaged $1.29 \%$ of total assets. The next section will address this concern by incorporating into the model resource costs associated with accepting deposits and/or making loans.

\section{Costly financial intermediation}

This section extends the model to allow for resource costs associated with servicing deposits and/or making loans. More precisely, it is now assumed that a bank with $D$ in deposits and $L$ in loans pays a cost $g(D, L)$ to service those financial contracts. The cost enters negatively in the calculation of the bank's net cash flow. 
I make the following assumptions on $g: g(D, L)$ is nonnegative, twice continuously differentiable, increasing in its first argument, strictly increasing in its second argument, convex, and homogenous of degree 1, i.e. it exhibits constant returns to scale. Note that linear costs are included as a special case.

For the rest, the model is the same as presented in section 1. It is, however, convenient to impose the following additional assumption on the utility function:

$$
\lim _{d \downarrow 0} \frac{u_{d}(c, d)}{u_{c}(c, d)}>\frac{g(1-\gamma, 1)}{1-\gamma} \text { for all } c>0
$$

This 'weak Inada' condition ${ }^{30}$ is imposed only to streamline the analysis of the equilibrium. If it fails to hold, there is an additional -empirically irrelevant-case to consider in which banks do not exist in equilibrium because the cost of intermediation is too high relative to the marginal value of liquidity, regardless of how scarce liquidity is. If that case applies, the model in any case closely resembles a standard growth model. ${ }^{31}$ The above assumption is sufficient, but not necessary, to rule out this empirically uninteresting case.

The introduction of the cost of intermediation has a direct effect only on the bank's decision problem. The rest of this section analyses the bank's decisions in the presence of $g$, and then moves on to describe how the equilibrium changes.

\section{Banks under costly financial intermediation}

With costly intermediation, the bank's cash flow is equal to $\left(R^{L}+\sigma \varepsilon\right) L-R^{D} D-g(D, L)$. The value of the bank to its shareholders right after the bank has raised $E$ in equity at the beginning of the period is now:

$$
\begin{gathered}
V^{B}(E)=\max _{L, D, \sigma} \mathbb{E}_{\varepsilon}\left[\left(\left(R^{L}+\sigma \varepsilon\right) L-R^{D} D-g(D, L)\right)^{+}\right] / R^{E} \\
\text { s.t. } \quad L=E+D \\
E \geq \gamma L \\
\sigma \in[0, \bar{\sigma}]
\end{gathered}
$$

The only difference with (5) is the presence of the resource cost $g(D, L)$.

\footnotetext{
${ }^{30} \lim _{d \downarrow 0} u_{d}(c, d)=\infty$ is a sufficient condition for the assumption to hold.

${ }^{31}$ Obviously, without banks, the welfare cost of increasing the bank capital requirement would be zero in this case.
} 
First, a similar argument as in section 1 can be used to characterize the choice of $\sigma$ conditional on $L$ and $D$. As before, the optimal solution entails either zero or maximum riskiness. Appendix $\mathrm{C}$ shows that the following is a sufficient condition for $\sigma=0$ :

$$
\bar{\sigma} \leq R^{L}-R^{D}(1-\gamma)-g(1-\gamma, 1)
$$

This is also a necessary condition when the capital requirement is binding. From the remainder of this section, unless explicitly stated otherwise, it is assumed that (24) holds.

Again, with $\sigma=0$ the bank's sub-problem in (23) is simplified. Since the algebra is fairly similar to that in section 1, the details are left to Appendix C. The appendix also contains an analysis of the bank's full problem, in which the bank also chooses how much equity to raise with the goal of maximizing its pre-issue value, $V^{B}(E)-E$. The result of that exercise can be conveniently summarized by stating the following versions of the first order conditions:

1. If the capital requirement is slack, then

$$
\begin{aligned}
& R^{E}=R^{D}+g_{D}(D, L) \\
& R^{L}=R^{E}+g_{L}(D, L)
\end{aligned}
$$

2. If the capital requirement binds, then $E=\gamma L$ and

$$
R^{L}=\gamma R^{E}+(1-\gamma) R^{D}+(1-\gamma) g_{D}(D, L)+g_{L}(D, L)
$$

In either case, $V^{B}(E)=E$.

The first case, a nonbinding capital requirement, requires that the bank be indifferent at the margin between financing its assets with deposits or equity and that the bank makes zero profit on making one more loan and financing it with equity (or deposits). The second requirement entails $R^{L}>R^{E}$, since $g_{L}(D, L)>0$ by assumption. However, if $R^{L}>R^{E}$, nonfinancial firms will strictly prefer equity finance to bank loans, as explained in the discussion of firms in section 1. There will be no demand for loans in that case, ${ }^{32}$ and banks will not exist. Hence,

\footnotetext{
${ }^{32}$ Technically, the demand for bank loans would be negative infinity. That is why $R^{L} \leq R^{E}$ is a requirement for a finite solution to the firm's problem. See section 2.
} 
if banks exist in equilibrium, with costly financial intermediation, the capital requirement always binds.

With the capital requirement binding, equation (25) holds. Since $D=(1-\gamma) L$ in this case, and using the fact that the partial derivatives of $g$ are homogenous of degree zero as well as Euler's theorem, this is easily simplified to

$$
R^{L}=\gamma R^{E}+(1-\gamma) R^{D}+g(1-\gamma, 1)
$$

Under costless financial intermediation, the rate on bank loans was simply equal to the appropriately weighted average of the returns on equity and deposits. Now, the return on bank loans also includes the term $g(1-\gamma, 1)$ - the resource cost of lending one additional unit and servicing $1-\gamma$ additional units of deposits to finance the loan. As constant returns to scale of $g$ implies that the marginal cost of increasing the scale equals the average cost, the bank still has zero profits: $V^{B}(E)=E$.

Note that the condition for $\sigma=0$, stated in (24), is seen to be equivalent to

$$
\bar{\sigma} \leq \gamma R^{E}
$$

the same condition as with $g=0$ (condition (10)). Since the capital requirement is binding, this condition is necessary as well as sufficient.

\section{Other agents}

As mentioned, the cost of intermediation has a direct effect only on the bank's decision problem. Nonetheless, a few comments on the decisions of nonfinancial firms and on the government are in order. For households, the analysis is exactly the same as before.

For nonfinancial firms, it has been shown that when $R^{L}=R^{E}$, firms are indifferent between equity and bank loans. In section 1 it was possible to assume without loss of generality that in that case firms opt for bank loans only. As will be clear shortly, with costly financial intermediation, such an assumption would now no longer be correct, so this assumption is dropped.

For the government, the budget constraint needs restating to take into account the effect of the cost of intermediation on the losses, if any, of the deposit insurance fund: 


$$
T_{t}=T+0.5\left(R_{t}^{D} D_{t}-\left(R_{t}^{L}-\sigma_{t}(1+2 \xi)\right) L_{t}-g\left(D_{t}, L_{t}\right)\right)^{+}
$$

\section{General equilibrium with costly intermediation}

The definition of equilibrium is essentially the same as in section 1 . However, since it will turn out to be necessary to explicitly consider the possibility that firm equity is strictly positive $\left(E^{F}>0\right)$, the market clearing conditions are modified to take this into account.

Given a government policy $\gamma$ and $T$, an equilibrium with costly intermediation is defined as a path of consumption, capital, deposits, equity holdings, bank loans and financial returns, for $t=0,1,2, \ldots$ such that:

1. Households, banks and nonfinancial firms all solve their maximization problems, described above, with taxes set according to (27);

2. All markets clear, i.e.

$$
\begin{aligned}
& d_{t}=D_{t} \\
& e_{t}=E_{t}+E_{t}^{F} \\
& K_{t}=E_{t}^{F}+L_{t} \\
& H_{t}=1
\end{aligned}
$$

and

$$
F\left(K_{t}, 1\right)-\sigma_{t} \xi K_{t}+(1-\delta) K_{t}=c_{t}+K_{t+1}+g\left(D_{t}, L_{t}\right)+T ;
$$

Again, I focus on the case that (10) holds: $S(T) \leq \gamma R_{t}^{E}$, so that $\sigma_{t}=0$ and $T_{t}=T$. Combining the market clearing conditions with equations (2), (3), (26), (11) and (12), it is possible to characterize the equilibrium in terms of a system in $\left(K_{t}, c_{t}\right)$ with $R_{t}^{E}, R_{t}^{L}$ and $d_{t}$ as auxiliary variables:

$$
\begin{aligned}
& K_{t}=F\left(K_{t-1}, 1\right)+(1-\delta) K_{t-1}-c_{t-1}-g(1-\gamma, 1) d_{t-1} /(1-\gamma)-T \\
& \beta^{-1}\left(u_{c}\left(c_{t-1}, d_{t-1}\right) / u_{c}\left(c_{t}, d_{t}\right)\right)=R_{t}^{E} \\
& F_{K}\left(K_{t}, 1\right)+1-\delta=R_{t}^{L}
\end{aligned}
$$

where $d_{t}$ and the relation between $R_{t}^{L}$ and $R_{t}^{E}$ are determined according to one of the following two cases. Let $\Delta \equiv(1-\gamma) \frac{u_{d}\left(c_{t},(1-\gamma) K_{t}\right)}{u_{c}\left(c_{t},(1-\gamma) K_{t}\right)}-g(1-\gamma, 1)$. Then: 
(a) If $\Delta \geq 0$, firms rely solely on bank loans and

$$
\begin{aligned}
& d_{t}=(1-\gamma) K_{t} \\
& R_{t}^{L}=R_{t}^{E}-(1-\gamma) \frac{u_{d}\left(c_{t}, d_{t}\right)}{u_{c}\left(c_{t}, d_{t}\right)}+g(1-\gamma, 1)
\end{aligned}
$$

Remark: $R_{t}^{L} \leq R_{t}^{E}, L_{t}=K_{t}$ and $E_{t}^{F}=0$. Remaining variables are determined through (3) and (11) with $H_{t}=1$.

(b) If $\Delta<0$, firms rely on a mix of equity and bank loans and

$$
\begin{aligned}
& (1-\gamma) \frac{u_{d}\left(c_{t}, d_{t}\right)}{u_{c}\left(c_{t}, d_{t}\right)}=g(1-\gamma, 1) \\
& R_{t}^{L}=R_{t}^{E}
\end{aligned}
$$

Remark: $L_{t}=d_{t} /(1-\gamma)<K_{t}$ and $E_{t}^{F}=K_{t}-L_{t}>0$. Remaining variables are determined through (3) and (11) with $H_{t}=1$. Assumption (22) guarantees that there exists a $d_{t}$ between 0 and $(1-\gamma) K_{t}$ such that (33) holds.

Thus, the spread between the required return on equity and the rate on bank loans is reduced by the cost of financial intermediation. However, if the cost of banking is sufficiently small relative to the value of liquidity services, bank loans are still strictly cheaper than equity finance and the equilibrium is qualitatively similar to the one with costless intermediation (and a binding capital requirement).

In contrast, if the cost of banking is high, in the sense that $\Delta<0$, then firms will use both equity and bank finance, in such proportion that, in equilibrium, their costs are exactly equal: $R_{t}^{L}=R_{t}^{E}$. This is consistent with zero profits in banking only if $(1-\gamma)$ times the spread between $R_{t}^{E}$ and $R_{t}^{D}$ exactly compensates for the resource cost of lending one unit and servicing $(1-\gamma)$ units of deposits, whence equation (33). ${ }^{33}$ This condition determines the equilibrium volume of deposits. As $L_{t}=d_{t} /(1-\gamma)$ with the binding capital requirement, it also pins down the right proportion between equity and bank finance,

It is interesting to note that in case (b) steady state superneutrality of the capital requirement $\gamma$ holds, in contrast to the result under costless financial

\footnotetext{
${ }^{33}$ The capital requirement still binds because $R_{t}^{E}-R_{t}^{D}=g(1-\gamma, 1) /(1-\gamma)>g_{D}(1-\gamma, 1)$, so the spread exceeds the marginal resource cost of deposits.
} 
intermediation. The reason is that $R_{t}^{L}=R_{t}^{E}$ in case (b) and the latter is simply $\beta^{-1}$ in steady state; this pins down the steady state capital stock through (30), which is then no different from the steady state capital stock obtained without any preference for liquidity (i.e. if $u_{d} \equiv 0$ ). In case (a), however, it is easy to verify that superneutrality fails for general $u$ ( ) as in section 1 .

In either case, though, I will show that welfare is affected by the capital requirement. The strategy for doing so is the same as in section 2. I present a constrained social planner's problem that replicates the decentralized equilibrium and then use that equivalence to derive a new formula for the marginal welfare cost of increasing $\gamma$.

\section{The social planner's problem with costly intermediation}

Define the following constrained social planner's problem:

$$
\begin{gathered}
V_{0}^{c i}(\theta)=\max _{\left\{c_{t}, d_{t}, L_{t}, K_{t+1}\right\}_{t=0}^{\infty}} \sum_{t=0}^{\infty} \beta^{t} u\left(c_{t}, d_{t}\right) \\
\text { s.t. } \quad F\left(K_{t}, 1\right)+(1-\delta) K_{t}=c_{t}+K_{t+1}+g\left(d_{t}, L_{t}\right)+T \\
(1-\gamma) L_{t}-d_{t} \geq 0 \\
K_{t}-L_{t} \geq 0
\end{gathered}
$$

Recall that $\theta=\left(\gamma, T, \delta, \beta, K_{0}\right)$. This problem differs from the one in section 2 not only by including the intermediation cost $g$, but also by allowing for the possibility that $E_{t}^{F}=K_{t}-L_{t}>0$.

Appendix D displays the first-order conditions to this problem and uses these to characterize the solution. It also shows that the resulting allocation is identical to the decentralized equilibrium with costly intermediation when $\sigma=0$ in that equilibrium (i.e. when $S(T) \leq \gamma R_{t}^{E}$ ). In other words, the constrained social planner's problem replicates the decentralized equilibrium and, as a consequence, welfare in the decentralized equilibrium equals $V_{0}^{c i}(\theta)$, the value of the objective function to the constrained social planner's problem with costly intermediation.

\section{A formula for the marginal welfare cost for the case of costly intermediation}

Again, the strategy is to exploit the equivalence of the constrained social planner's problem and the decentralized equilibrium to measure the marginal 
effect on welfare of a change in the capital requirement. Call the current period period 0 and assume government policy is such that (10) holds: $S(T) \leq \gamma R_{t}^{E}$ for all $t \geq 0$, so that $\sigma_{t}=0$ in the decentralized equilibrium. The marginal effect on welfare of raising $\gamma$, without altering $T$, is now:

$$
\frac{\partial V_{0}^{c i}(\theta)}{\partial \gamma}=\frac{\partial \ell_{0}^{c i}(\theta)}{\partial \gamma}=-\sum_{t=0}^{\infty} \beta^{t} \chi_{t}^{s p} L_{t}
$$

where $\chi_{t}^{s p}$ is the Kuhn Tucker multiplier on the capital requirement. Using the first order conditions $(d)$ and $(c)$ to the social planner's problem (shown in Appendix D),

$$
\chi_{t}^{s p} L_{t}=\left(u_{d}\left(c_{t}, d_{t}\right)-u_{c}\left(c_{t}, d_{t}\right) g_{D}\left(d_{t}, L_{t}\right)\right) L_{t}
$$

Since the allocations of $K_{t}, c_{t}$ and $d_{t}$ are identical to those of the decentralized equilibrium, I can use the decentralized equilibrium values for the variables on the right hand side of this equation. Moreover, in the decentralized equilibrium, we have, using (3),

$$
\left(u_{d}\left(c_{t}, d_{t}\right)-u_{c}\left(c_{t}, d_{t}\right) g_{D}\left(d_{t}, L_{t}\right)\right) L_{t}=u_{c}\left(c_{t}, d_{t}\right)\left(R_{t}^{E}-R_{t}^{D}-g_{D}\left(d_{t}, L_{t}\right)\right)(1-\gamma)^{-1} d_{t}
$$

where I have also used the result that the capital requirement binds, so that $d_{t}=(1-\gamma) L_{t}$.

Next, assume that the economy is in steady state in period 0 . Then the first order approximation of the welfare effect of an increase in $\gamma$ by $\Delta \gamma$ simplifies as follows:

$$
\frac{\partial V_{0}^{c i}(\theta)}{\partial \gamma} \Delta \gamma=-\frac{\chi_{0}^{s p} L_{0}}{1-\beta} \Delta \gamma=-\frac{u_{c}\left(c_{0}, d_{0}\right)\left(R_{0}^{E}-R_{0}^{D}-g_{D}\left(d_{t}, L_{t}\right)\right) d_{0}}{(1-\beta)(1-\gamma)} \Delta \gamma
$$

Again, it is useful to compare this to the welfare effect of a permanent change in consumption by a factor $(1+v)$, given to a first order approximation in equation (20) if period 0 is a steady state. The result is the following 
Proposition 2: Assume the economy is in steady state in period 0 and (10) holds. Consider permanently increasing $\gamma$ by $\Delta \gamma$. With costly financial intermediation, a first-order approximation to the resulting welfare loss, expressed as the welfareequivalent permanent relative loss in consumption, is

$$
v^{c i}(\Delta \gamma)=\frac{d_{0}}{c_{0}}\left(R_{0}^{E}-R_{0}^{D}-g_{D}\left(d_{0}, L_{0}\right)\right)(1-\gamma)^{-1} \Delta \gamma
$$

This formula differs from the one derived for costless intermediation in that it subtracts the marginal resource cost of servicing deposit contracts from the spread between the returns on equity and deposits. ${ }^{34}$ The intuition for this change is straightforward: If liquidity creation is costly, then, even in the absence of a binding capital requirement, this creates a spread between the returns on equity and deposits, as banks need to be compensated for this cost. It is only to the extent that the spread exceeds the marginal resource cost of the deposits that a scarcity of deposits due to the binding capital requirement is revealed. Only then is there a welfare effect at the margin.

It is worth emphasizing that the formula is valid whether the equilibrium is characterized by pure bank finance or by mixed bank and equity finance. How one might measure, or bound, the marginal cost of deposits is addressed in the next section.

\section{Further Empirical Results}

Arguably the most conservative way of measuring the new term, $g_{D}(D, L)$, in the expression for the welfare cost (35) is to calculate an upper and lower bound based only on the assumptions already made, namely that the cost $g$ is nondecreasing and exhibits constant returns to scale, which imply ${ }^{35}$

$$
0 \leq g_{D}(D, L) \leq \frac{g(D, L)}{D}
$$

\footnotetext{
${ }^{34}$ Note that if $g=0$, the formula specializes to the one derived in proposition 1 . Thus, the formula applies in both cases.

${ }^{35}$ With decreasing returns to scale these bounds would also apply. The assumption that $g_{L}>0$ actually implies that the second inequality is strict.
} 
Setting $g_{D}=0$ yields the same result as with costless financial intermediation. Section 3 found that $v(\Delta \gamma)=0.0216 \Delta \gamma$ in this case. To implement the upper bound, $g$ is measured as net noninterest cost (Total Noninterest Expense minus Total Noninterest Income). The average ratio of net noninterest cost to deposits for 1993-2002 is 0.0187 (i.e. 1.87 percent). With this upper bound for $g_{D}$ we get the following lower bound for the welfare cost:

$$
v^{c i}(\Delta \gamma) \geq 0.61 \times(0.0318-0.0187) \times(1-0.096)^{-1} \Delta \gamma=0.0089 \Delta \gamma
$$

Naturally, recognizing that financial intermediation is costly leads to a somewhat lower estimate of the marginal welfare cost. According to this method, the welfare loss of raising the capital requirement by $\Delta \gamma=0.1$ is somewhere between $0.89 \%$ and $2.16 \%$ of consumption (permanently). [Note: alternative, less conservative estimates are to be added.]

\section{Conclusion}

The welfare costs of bank capital requirements found in this paper are neither trivial nor gigantic. One interpretation of this finding is that regulators face an important trade-off between, on the one hand, keeping the effective capital requirement ratio as low as possible and, on the other hand, limiting the supervision and compliance cost associated with capital adequacy regulation, all the while keeping the probability of bank failure acceptably low. It is not obvious that the current trend towards a more complex regulatory regime is outrageously wrong. 


\section{APPENDIX A. RISKY FIRMS}

Since there is no asymmetric information between the bank and the firm, the optimal financial contract will have the repayment depend on the realization of the shock $\varepsilon$. Let $\tilde{R}^{L}(\varepsilon)$ denote the contractual loan repayment rate as a function of the shock. Profits are of a risky firm are:

$$
\tilde{\pi}^{F}=F(K, H)+\sigma_{R F} \varepsilon K+(1-\delta) K-w H-\tilde{R}^{L}(\varepsilon) K
$$

For ease of exposition define

$$
f(K) \equiv \max _{H} F(K, H)+(1-\delta) K-w H
$$

One of the results in the main text is that, in an equilibrium in which riskless firms exist, they have zero profits and indeterminate scale, so that

$$
f(K)=R^{L} K
$$

where $R^{L}$ is the equilibrium riskless loan rate. Hence, given an optimal choice for $H$, profits of the risky firm equal

$$
\tilde{\pi}^{F}=R^{L} K+\sigma_{R F} \varepsilon K-\tilde{R}^{L}(\varepsilon) K
$$

Limited liability of the shareholders implies $\tilde{\pi}^{F} \geq 0$ in each state. Hence,

$$
\tilde{R}^{L}(\varepsilon) \leq R^{L}+\sigma_{R F} \varepsilon
$$

The right hand side is the most the bank can charge in each state without violating limited liability. Suppose the loan rate equals this upper bound in each state. Then, from assumption (4), it follows that

$$
\mathbb{E}_{\varepsilon}\left[\tilde{R}^{L}(\varepsilon)\right]=R^{L}-\xi \sigma_{R F}<R^{L}
$$

Since this is still a worse expected return than for a nonrisky loan, the risky firm cannot hope to get better terms, so that, in fact, $\tilde{R}^{L}(\varepsilon)=R^{L}+\sigma_{R F} \varepsilon$, if any lending to risky firms occurs.

With this loan contract, the risky firm has zero (expected) profits, so its participation constraint is satisfied. As mentioned in the main text, this implies that a bank can create a portfolio of riskiness $\sigma$ by directing a fraction $\sigma / \sigma_{R F}$ of its lending to risky firms with perfectly correlated shocks (e.g. one risky firm).

Finally, it is easily verified that labor demand of a risky firm satisfies the same first-order condition (11) as for a nonrisky firm. 


\section{APPENDiX B. PROOF OF FAILURE OF SUPERNEUTRALITY}

First, I state explicitly a convenient assumption that bounds taxes from above in order to guarantee existence of a steady state equilibrium with positive consumption for the assumed utility function (see footnote 21). Define $\hat{K}$ by writing

$$
F_{K}(\hat{K}, 1)+1-\delta \equiv \beta^{-1}
$$

Note that $\hat{K}$ exists and is unique. $\hat{K}$ is the steady state level of the capital stock under the assumption $a=0$ (i.e. $u_{d}(c, d) \equiv 0$, so that the model is not materially different from the standard growth model). I assume that

$$
T<F_{H}(\hat{K}, 1) 1
$$

That is, taxes are lower than aggregate wage income at $\hat{K} \cdot{ }^{36}$

With $a>0, u_{d}(c, d)>0$ everywhere, so the capital stock is determined by system (15) which for a steady state and the assumed functional form of $u($ ) simplifies to

$$
\begin{aligned}
& F_{K}\left(K^{*}, 1\right)+1-\delta=\beta^{-1}-(1-\gamma) a\left(\frac{c^{*}}{(1-\gamma) K^{*}}\right)^{1 / \eta} \text { and } \\
& F\left(K^{*}, 1\right)+\delta K^{*}=c^{*}+T
\end{aligned}
$$

where starred variables denote steady state levels. Equivalently,

$$
F_{K}\left(K^{*}, 1\right)+1-\delta=\beta^{-1}-a(1-\gamma)^{(\eta-1) / \eta} \Psi\left(K^{*}\right)^{1 / \eta}
$$

with

$$
\Psi(K) \equiv(F(K, 1)-T) / K-\delta
$$

Since $c^{*} / K^{*}=\Psi\left(K^{*}\right), c^{*} \geq 0 \Leftrightarrow \Psi\left(K^{*}\right) \geq 0 \Leftrightarrow K^{*} \in[\underline{K}, \bar{K}]$, where $\underline{K}, \bar{K}$ are the two solutions to $F(K, 1)-\delta K=T .^{37}$

Using assumption (37), the definition of $\hat{K}$ (36), and Euler's theorem, it is straightforward to show that $\Psi(\hat{K})>0$, so that $\hat{K} \in(\underline{K}, \bar{K})$. Moreover, again using Euler's theorem,

$$
\Psi^{\prime}(K)=\left(T-F_{H}(K, 1)\right) / K^{2}
$$

\footnotetext{
${ }^{36}$ Recall that $H=1$ in equilibrium. The assumption is sufficient but not necessary.

${ }^{37}$ The two roots exist since $\Psi(\hat{K})>0$, as explained in the next paragraph, and because $F$ satisfies the Inada conditions.
} 
Define $\tilde{K}$ by writing $F_{H}(\tilde{K}, 1) \equiv T$. Note that $\tilde{K}$ exists and is unique, $\tilde{K}<\hat{K}$ by (37) and $\Psi^{\prime}(K)>(<) 0$ iff $K<(>) \tilde{K}$. The last fact also implies that $\tilde{K}>\underline{K}$.

Since $\tilde{K}<\hat{K}<\bar{K}$, as we let $K$ increase from $\tilde{K}$ to $\bar{K}$, the left-hand side of (38), $F_{K}(K, 1)+1-\delta$, drops, continuously and monotonically, from a value strictly greater than $\beta^{-1}$ to a value strictly less than $\beta^{-1}{ }^{38}$ Again, as we let $K$ increase from $\tilde{K}$ to $\bar{K}$, the right-hand side of (38), $\beta^{-1}-(1-\gamma) a \Psi(K)^{1 / \eta}$, rises, continuously and monotonically, from a value strictly less than $\beta^{-1}$ to exactly $\beta^{-1}$ (as $\Psi(\bar{K}) \equiv 0$ ). Hence, there is exactly one $K^{*}$ in $[\tilde{K}, \bar{K}]$ satisfying (38). By a similar argument it is easy to show that there is no $K^{*}$ in $[\underline{K}, \tilde{K})$ satisfying (38). Hence, there is a unique steady state level of the capital stock. It is interesting to note that its marginal product is less than $\beta^{-1}$, so $K^{*}$ exceeds $\hat{K}$, the steady state level of capital without liquidity preference.

Total differentiation of equation (38) with respect to $K^{*}$ and $\gamma$ yields:

$$
\frac{d K^{*}}{d \gamma}=\frac{-a((\eta-1) / \eta)(1-\gamma)^{-1 / \eta} \Psi\left(K^{*}\right)^{1 / \eta}}{F_{K K}\left(K^{*}, 1\right)+a(1-\gamma)^{(\eta-1) / \eta} \Psi\left(K^{*}\right)^{(1-\eta) / \eta} \Psi^{\prime}\left(K^{*}\right)}
$$

$\tilde{K}<K^{*}<\bar{K}$ implies that $\Psi\left(K^{*}\right)>0$ and $\Psi^{\prime}\left(K^{*}\right)<0$. Since, in addition, $F_{K K}\left(K^{*}, 1\right)<0$,

$$
\operatorname{sign}\left(d K^{*} / d \gamma\right)=\operatorname{sign}(\eta-1)
$$

QED.

\footnotetext{
${ }^{38}$ In fact, it is possible to show that $F_{K}(\bar{K}, 1)+1-\delta<1$ by using the definition of $\bar{K}$ and assumption (37).
} 


\section{APPENDIX C. THE BANK'S PROBLEM WITH COSTLY FINANCIAL INTERMEDIATION}

Expected dividends are now

$$
\begin{aligned}
\mathbb{E}_{\varepsilon} & {\left[\left(\left(R^{L}+\sigma \varepsilon\right) L-R^{D} D-g(D, L)\right)^{+}\right] } \\
& =\left\{\begin{array}{cl}
\left(R^{L}-\sigma \xi\right) L-R^{D} D-g(D, L) & \text { if }\left(R^{L}-\sigma(1+2 \xi)\right) L-R^{D} D-g(D, L) \geq 0 \\
0.5\left(\left(R^{L}+\sigma\right) L-R^{D} D-g(D, L)\right) & \text { otherwise }
\end{array}\right.
\end{aligned}
$$

As before, expected dividends are a quasi-linear, convex function of $\sigma$, so the optimal choice of riskiness is at a boundary of the feasible set $[0, \bar{\sigma}]$. By evaluating expected dividends under $\sigma=0$ versus $\sigma=\bar{\sigma}$, and using the constant returns to scale of $g$, it is easy to verify that

$$
\begin{aligned}
& \sigma=0 \text { iff } \bar{\sigma} \leq R^{L}-R^{D}(D / L)-g(D / L, 1) \\
& \sigma=\bar{\sigma} \text { otherwise }
\end{aligned}
$$

Again, for convenience it is assumed that the bank chooses $\sigma=0$ when bank is indifferent between the two choices at $\bar{\sigma}=R^{L}-R^{D}(D / L)-g(D / L, 1)$. Because $E=L-D \geq \gamma L$, a sufficient condition for $\sigma=0$ is:

$$
\bar{\sigma} \leq R^{L}-R^{D}(1-\gamma)-g(1-\gamma, 1)
$$

This is also a necessary condition if $E=\gamma L$, i.e. if the capital requirement is binding.

If (24) holds, the bank's sub-problem in (23) simplifies to:

$$
V^{B}(E)=\max _{L}\left(R^{L} L-R^{D}(L-E)-g(L-E, L)\right) / R^{E}
$$

s.t. $E-\gamma L \geq 0$

where I have substituted the balance sheet identity, $D=L-E$, into the objective function. While this sub-problem is straightforward to solve, it economizes on algebra to characterize the solution as part of an analysis of the bank's full problem, which includes the choice on how much equity to raise. In choosing $E$, the bank maximizes its pre-issue value, $V^{B}(E)-E$ :

$$
\begin{aligned}
\pi^{B}= & \max _{E}\left(V^{B}(E)-E\right) \\
= & \max _{E, L}\left(R^{L} L-R^{D}(L-E)-g(L-E, L)\right) / R^{E}-E \\
& \quad \text { s.t. } \quad E-\gamma L \geq 0
\end{aligned}
$$

The first-order conditions are: 
(L) $\quad R^{L}-R^{D}-g_{D}(D, L)-g_{L}(D, L)=\gamma R^{E} \chi$

(E) $\quad R^{D}+g_{D}(D, L)=(1-\chi) R^{E}$

where $\chi$ is the Kuhn-Tucker multiplier associated with the capital requirement: $\chi \geq 0$ and $\chi(E-\gamma L)=0$. There are two cases to consider:

If $\chi=0$, i.e. if the capital requirement is slack, the first-order conditions specialize to

$$
\begin{aligned}
& R^{E}=R^{D}+g_{D}(D, L) \\
& R^{L}=R^{E}+g_{L}(D, L)
\end{aligned}
$$

If $\chi>0$, i.e. if the capital requirement binds, $E=\gamma L$ and the first-order conditions yield

$$
R^{L}=\gamma R^{E}+(1-\gamma) R^{D}+(1-\gamma) g_{D}(D, L)+g_{L}(D, L)
$$

\section{APPENDIX D. THE CONSTRAINED SOCIAL PLANNER'S PROBLEM WITH COSTLY FINANCIAL INTERMEDIATION}

The Lagrangian and the first-order conditions to this problem are:

$$
\begin{gathered}
\ell_{0}^{c i}(\theta)=\max _{\left\{c_{t}, d_{t}, L_{t} K_{t+1}\right\}_{t=0}^{\infty} \sum_{t=0}^{\infty}} \sum_{t=0}^{\infty} \beta^{t}\left\{u\left(c_{t}, d_{t}\right)+\lambda_{t}^{s p}\left[F\left(K_{t}, 1\right)+(1-\delta) K_{t}-c_{t}-g\left(d_{t}, L_{t}\right)-K_{t+1}-T\right]\right. \\
\left.+\chi_{t}^{s p}\left[(1-\gamma) L_{t}-d_{t}\right]+\mu_{t}^{s p}\left[K_{t}-L_{t}\right]\right\}
\end{gathered}
$$

$$
\begin{aligned}
& u_{c}\left(c_{t}, d_{t}\right)=\lambda_{t}^{s p} \\
& u_{d}\left(c_{t}, d_{t}\right)=\lambda_{t}^{s p} g_{D}\left(d_{t}, L_{t}\right)+\chi_{t}^{s p} \\
& (1-\gamma) \chi_{t}^{s p}=\lambda_{t}^{s p} g_{L}\left(d_{t}, L_{t}\right)+\mu_{t}^{s p} \\
& \lambda_{t}^{s p}\left[F_{K}\left(K_{t}, 1\right)+1-\delta\right]-\beta^{-1} \lambda_{t-1}^{s p}+\mu_{t}^{s p}=0
\end{aligned}
$$

with $\chi_{t}^{s p} \geq 0, \chi_{t}^{s p}\left[(1-\gamma) K_{t}-d_{t}\right]=0, \mu_{t}^{s p} \geq 0$ and $\mu_{t}^{s p}\left[K_{t}-L_{t}\right]=0$. Since $g_{L}>0$, the first order conditions with respect to consumption and loans imply $\chi_{t}^{s p}>0$, so that the 'capital requirement' binds: $d_{t}=(1-\gamma) L_{t}$. There are thus only two cases to consider:

(a). If $\mu_{t}^{s p}>0$, then $K_{t}=L_{t}$ and, since $\chi_{t}^{s p}>0, d_{t}=(1-\gamma) L_{t}=(1-\gamma) K_{t}$. Rewriting the first-order condition with respect to $K$, 


$$
\begin{aligned}
F_{K}\left(K_{t}, 1\right)+1-\delta & =\beta^{-1} \lambda_{t-1}^{s p} / \lambda_{t}^{s p}-\mu_{t}^{s p} / \lambda_{t}^{s p} \\
& =\frac{\beta^{-1} u_{c}\left(c_{t-1}, d_{t-1}\right)}{u_{c}\left(c_{t}, d_{t}\right)}-\left\{(1-\gamma) \frac{u_{d}\left(c_{t}, d_{t}\right)}{u_{c}\left(c_{t}, d_{t}\right)}-g(1-\gamma, 1)\right\}
\end{aligned}
$$

where the last equality follows the first order conditions with respect to $d$ and $L$ and the homogeneity of $g$. Since the term in curly brackets equals $\mu_{t}^{s p} / \lambda_{t}^{s p}$, it must be strictly positive. As $d_{t}=(1-\gamma) K_{t}$ here, this case thus requires that $\Delta>0$. (For convenience, it is recalled that $\left.\Delta \equiv(1-\gamma) u_{d}\left(c_{t},(1-\gamma) K_{t}\right) / u_{c}\left(c_{t},(1-\gamma) K_{t}\right)-g(1-\gamma, 1).\right)$

(b). If $\mu_{t}^{s p}=0$, the first order conditions yield:

$$
\begin{aligned}
& F_{K}\left(K_{t}, 1\right)+1-\delta=\beta^{-1} u_{c}\left(c_{t-1}, d_{t-1}\right) / u_{c}\left(c_{t}, d_{t}\right) \\
& u_{d}\left(c_{t}, d_{t}\right)=u_{c}\left(c_{t}, d_{t}\right) g(1-\gamma, 1) /(1-\gamma)
\end{aligned}
$$

The second equation is obtained by combining the first order conditions with respect to $d$ and $L$. As case (a) requires $\Delta>0$, case (b) must apply if $\Delta \leq 0$. If $\Delta \leq 0$, then by assumption (22) there exists a positive $d_{t} \leq(1-\gamma) K_{t}$ satisfying this equation.

Combining the above equations, including the social resource constraint and the binding capital requirement, it is apparent that the allocations of $K_{t}, c_{t}$ and $d_{t}$ are identical to those of the decentralized equilibrium summarized above in equations (28) through (34). Case (a) corresponds to the case of pure bank finance (also termed 'case (a)' in the main text), while case (b) corresponds to firms relying on both equity and bank finance (again, same label in the main text). Hence, this constrained social planner's problem replicates the decentralized equilibrium when $\sigma=0$ in the decentralized equilibrium and financial intermediation is costly. 


\section{References}

Allen, Franklin, and Douglas Gale, 2003. "Capital Adequacy Regulation: In Search of a Rationale" in Economics in an Imperfect World: Essays in Honor of Joseph Stiglitz, edited by R. Arnott, B. Greenwald, R. Kanbur and B. Nalebuff, Cambridge, MA: MIT Press 2003, 83-109.

Diamond, Douglas and Philip Dybvig, 1983. "Bank Runs, Deposit Insurance, and Liquidity." Journal of Political Economy 91, 401-19.

Diamond, Douglas W., and Raghuram G. Rajan, 2000. “A Theory of bank Capital”, Journal of Finance, December.

Dewatripont, Mathias, and Jean Tirole, 1994. The Prudential Regulation of Banks, MIT Press, Cambridge, MA.

Feenstra, Robert, 1986. "Functional Equivalence between Liquidity Costs and the Utility of Money”, Journal of Monetary Economics 17, pp. 73-85.

Giammarino, Ronald M., Tracy R. Lewis, and David Sappington, 1993. “An Incentive Approach to Banking Regulation”, Journal of Finance, 48(4), pp. 152342.

Gorton, Gary, and Andrew Winton, 2000. "Liquidity Provision, the Cost of Bank Capital, and the Macroeconomy”, working paper, University of Minnesota.

Lucas, Robert E, Jr, 2000. "Inflation and Welfare”, Econometrica, vol. 68, no. 2, March, pp. 247-74.

Sidrauski, Miguel, 1967a. "Rational Choice and Patterns of Growth in a Monetary Economy”, American Economic Review, May, 57(2).

Sidrausky, Miguel, 1967b. “Inflation and Economic Growth”, Journal of Political Economy, 75 (Dec.), 798-810.

Van den Heuvel, Skander J., 2004. “The Bank Capital Channel of Monetary Policy”, University of Pennsylvania, http://finance.wharton.upenn.edu/ vdheuvel/BCC.pdf 